\title{
Treatment of a congenital esophageal fistula by injection of autologous fat
}

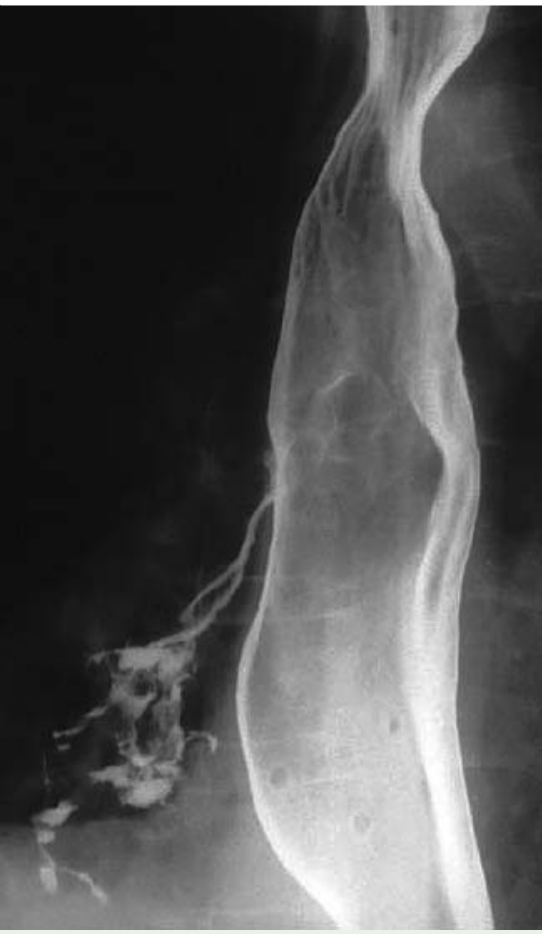

Fig. 1 Initial esophagogram before treatment, clearly showing a leak of contrast towards the tracheobronchial tree.

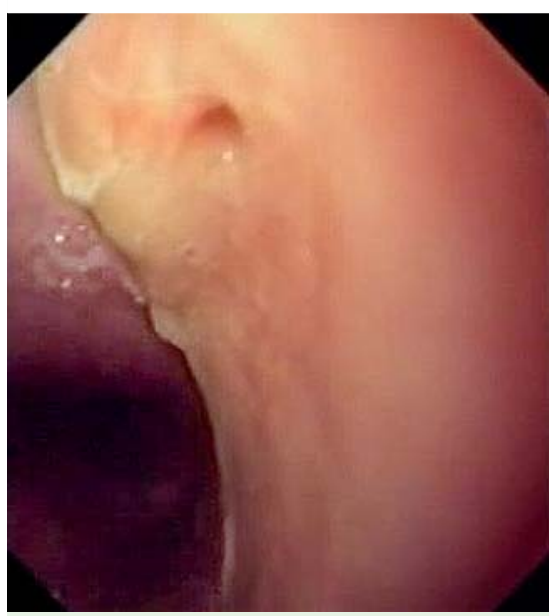

Fig. 2 Endoscopic image of the esophageal fistula.
The injection of autologous free fat obtained by suction-assisted lipectomy for the correction of soft tissue defects is a common procedure in plastic surgery. This procedure has also been used to prevent aspiration after vocal fold paralysis [1], and to treat vesicoureteral reflux [2]. Tracheo-esophageal fistula may present as an isolated defect or it may be associated with esophageal atresia. The treatment of congenital tracheo-esophageal fistulas is usually based on surgical procedures [3]. We present a preliminary report of a new endoscopic mode of therapy.

A 55-year-old man suffered from pneumonia and had frequent coughing episodes, especially after swallowing liquids. An orifice was identified by esophagogram ( $\bullet$ Fig. 1) and by endoscopy ( $\bullet$ Fig.2). Fatty tissue was obtained from the abdominal subcutaneous tissue by a suction-assisted procedure. A total of $60 \mathrm{~mL}$ of fatty tissue was obtained. After centrifugation at $3000 \mathrm{rpm}$ for 3 minutes, three layers were clearly visible ( $\bullet$ Fig.3): at the bottom, a component containing mainly blood residues and serum; in the middle, presumably viable fatty tissue; and, finally, at the top, an oily component that was discarded.

Several passes of a biopsy probe were carried out in order to traumatize the fistulous surface and thus gain adhesiveness. Next, some $15-20 \mathrm{~mL}$ of the infranatant solution, the presumably viable fatty tissue, was injected using a pressurized injection device and a 17 - to $18-G$ cannula, to close the fistula.

Ten months later, endoscopic ultrasonography revealed a hyperechoic collection (๑ Fig.4), although a smaller esophageal mucosal orifice still persisted. An additional therapeutic session was decided on. Two years later ( Fig.5), an esophagogram did not reveal a fistula ( $\bullet$ Fig.6), and the patient remains asymptomatic 11 years later.

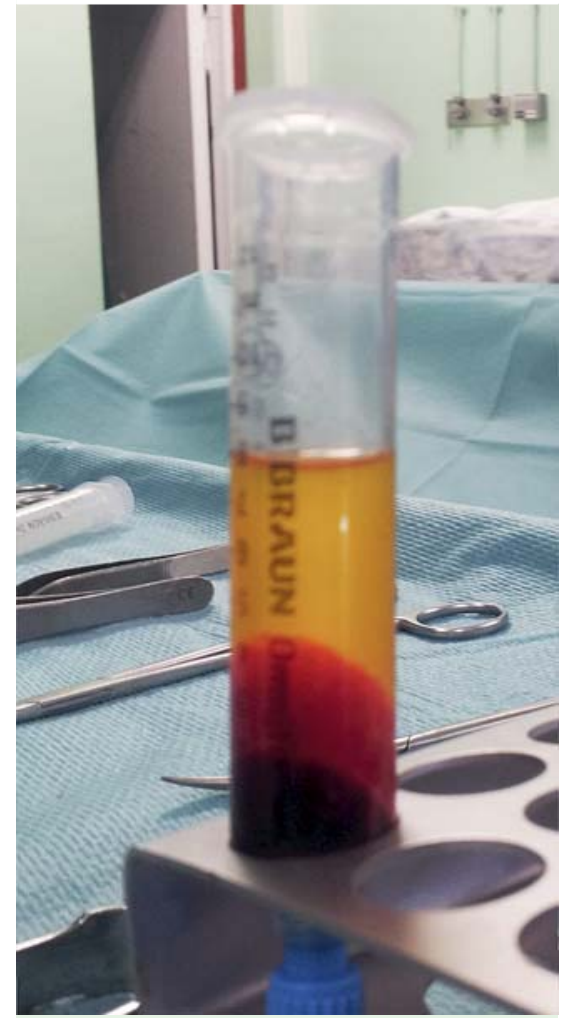

Fig. 3 Fat obtained by liposuction and managed by centrifugation. The three layers are apparent.

This preliminary report confirms that injection of autologous fatty tissue can persist as a long-lasting graft, suggesting several endoscopic applications.

Endoscopy_UCTN_Code_TTT_1AO_2AI

Competing interests: None 


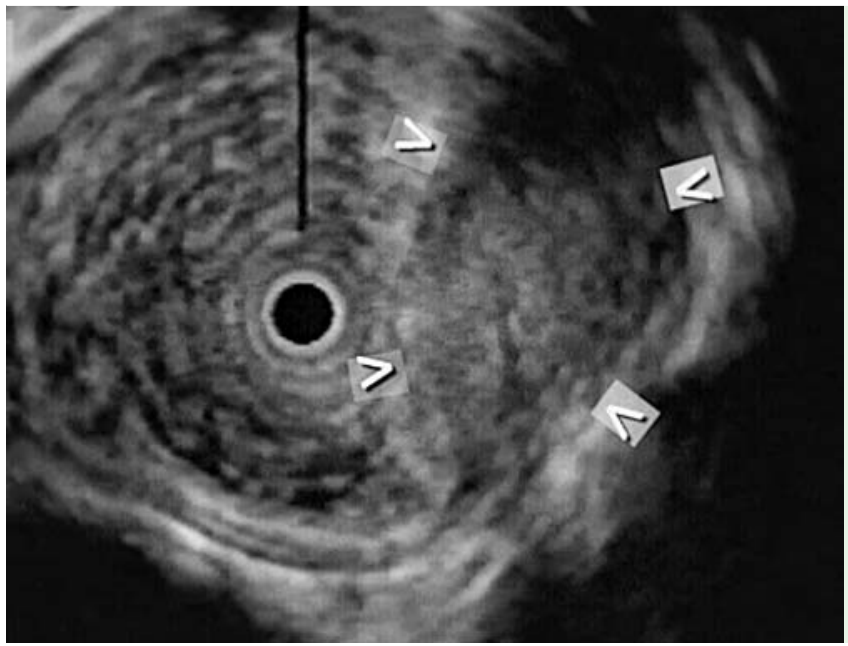

Fig. 4 Endoscopic ultrasonogram of the fatty deposit (arrowheads).

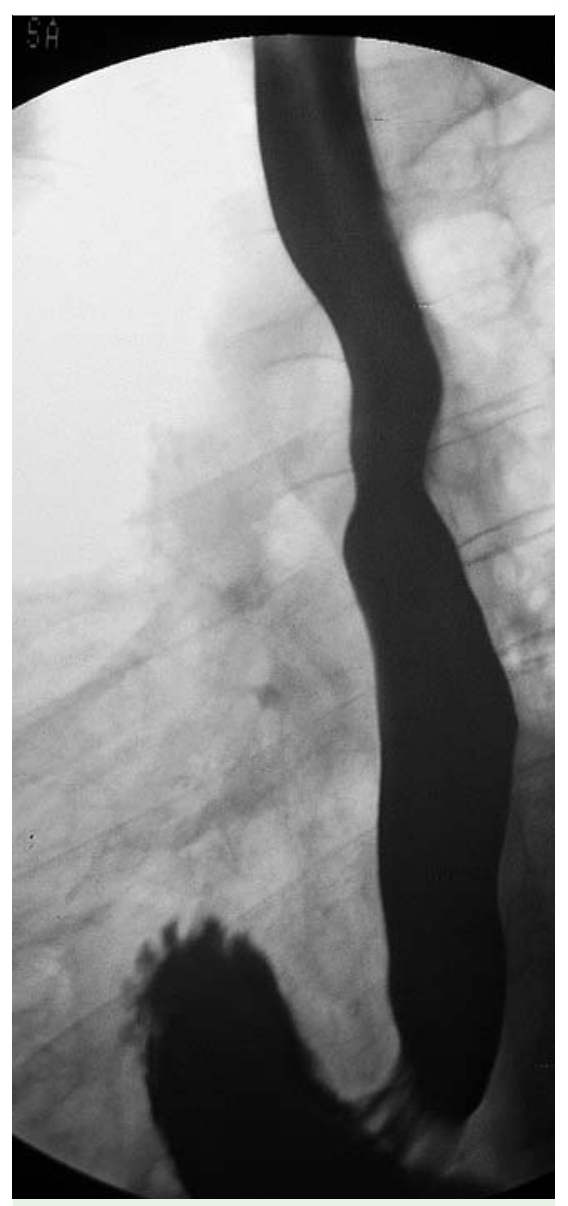

Manuel Moretó ${ }^{1}$, Javier Gabilondo², Fernando Fernandez-Samaniego ${ }^{2}$

${ }^{1}$ Department of Gastroenterology, Hospital Universitario de Cruces, Barakaldo, Spain

2 Department of Plastic Surgery, Hospital Universitario de Cruces, Barakaldo, Spain

\section{References}

1 Sato K, Umeno H, Nakashima T. Autologous fat injection laryngohypopharyngoplasty for aspiration after vocal fold paralysis. Ann Otol Rhinol Laryngol 2004; 113: 87-92

2 Matthews RD, Christensen JP, Canning DA. Persistence of autologous free fat transplant in bladder submucosa of rats. J Urol 1994; 152: 819-821

3 Genty E, Attal P, Nicollas $R$ et al. Congenital tracheoesophageal fistula without esophageal atresia. Int J Pediatr Otorhinolaryngol 1999; 48: $231-238$

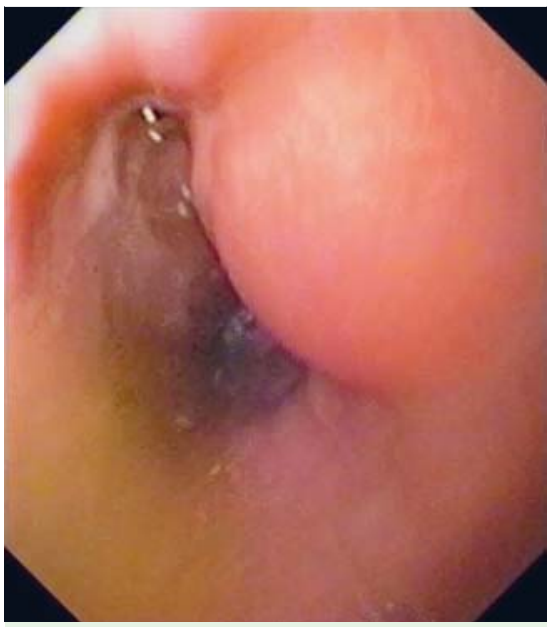

Fig. 5 Endoscopic image of protruding esophageal treated area 2 years after injection.

Bibliography

Dol http://dx.doi.org/

10.1055/s-0033-1359117

Endoscopy 2014; 46: E54-E55

(c) Georg Thieme Verlag KG

Stuttgart · New York

ISSN 0013-726X

Corresponding author

Manuel Moretó, MD

Department of Gastroenterology

Hospital Universitario de Cruces

Pl. de Cruces s/n

Barakaldo 48903

Spain

Fax: +34-94-6006358

mmoretoc@gmail.com

Fig. 6 Later esophagogram showing no fistulous leak. 